\title{
Motor neuropathy in porphobilinogen deaminase-deficient mice imitates the peripheral neuropathy of human acute porphyria
}

\author{
Raija L.P. Lindberg, ${ }^{1}$ Rudolf Martini, ${ }^{2}$ Matthias Baumgartner, ${ }^{1}$ Beat Erne, ${ }^{3}$ Jacques Borg, ${ }^{4}$ \\ Jürgen Zielasek, ${ }^{2}$ Kenneth Ricker, ${ }^{2}$ Andreas Steck, ${ }^{3}$ Klaus V. Toyka, ${ }^{2}$ and Urs A. Meyer ${ }^{1}$
}

\author{
${ }^{1}$ Biozentrum, University of Basel, CH-4056 Basel, Switzerland \\ ${ }^{2}$ Department of Neurology and Division of Developmental Neurobiology, Julius-Maximilians-Universität, D-97080 Würzburg, \\ Germany \\ ${ }^{3}$ Department of Clinical Neurology and Department of Research, University Hospital, CH-4031 Basel, Switzerland \\ ${ }^{4}$ Neurofit S.A., F-7400 Illkirch, France
}

Address correspondence to: Urs A. Meyer, Department of Pharmacology, Biozentrum, University of Basel, Klingelbergstrasse 70, CH-4056 Basel, Switzerland. Phone: 41-61-267-22-20; Fax: 41-61-267-22-08;

E-mail: meyer2@ubaclu.unibas.ch

Received for publication December 7, 1998, and accepted in revised form March 1, 1999.

\begin{abstract}
Acute porphyrias are inherited disorders caused by partial deficiency of specific heme biosynthesis enzymes. Clinically, porphyrias are manifested by a neuropsychiatric syndrome that includes peripheral neuropathy. Although much is known about the porphyrias' enzyme defects and their biochemical consequences, the cause of the neurological manifestations remains unresolved. We have studied porphyric neuropathy in mice with a partial deficiency of porphobilinogen deaminase (PBGD). PBGDdeficient mice $\left(\mathrm{PBGD}^{-/-}\right)$imitate acute porphyria through massive induction of hepatic $\delta$-aminolevulinic acid synthase by drugs such as phenobarbital. Here we show that $\mathrm{PBGD}^{-/-}$mice develop impairment of motor coordination and muscle weakness. Histologically femoral nerves of $\mathrm{PBGD}^{-/-}$mice exhibit a marked decrease in large-caliber $(>8 \mu \mathrm{m})$ axons and ultrastructural changes consistent with primary motor axon degeneration, secondary Schwann cell reactions, and axonal regeneration. These findings resemble those found in studies of affected nerves of patients with acute porphyria and thus provide strong evidence that PBGD deficiency causes degeneration of motor axons without signs of primary demyelination, thereby resolving a long-standing controversy. Interestingly, the neuropathy in $\mathrm{PBGD}^{-/-}$mice developed chronically and progressively and in the presence of normal or only slightly (twofold) increased plasma and urinary levels of the putative neurotoxic heme precursor $\delta$-aminolevulinic acid. These data suggest that heme deficiency and consequent dysfunction of hemeproteins can cause porphyric neuropathy.
\end{abstract}

J. Clin. Invest. 103:1127-1134 (1999).

\section{Introduction}

Four types of acute hepatic porphyria - acute intermittent porphyria (AIP), hereditary coproporphyria (HCP), variegate porphyria (VP), and $\delta$-aminolevulinic acid dehydratase (ALAD) deficiency porphyria - are clinically associated with an identical neurological syndrome. Manifestations of acute, life-threatening attacks include autonomic neuropathy with abdominal pain, vomiting, constipation, hypertension, tachycardia, and bladder dysfunction. Other manifestations are peripheral neuropathy causing motor weakness and paralysis and mental symptoms that occur without detectable morphological anomalies in the brain (1-4).

Acute porphyrias result from dominantly (AIP, HCP, $\mathrm{VP}$ ) or recessively (ALAD deficiency) inherited partial deficiency of specific enzymes in heme biosynthesis. Attacks of clinical symptoms frequently are precipitated by drugs, alcohol, fasting, or hormonal changes associated with the menstrual cycle (3).

The pathogenesis of porphyric neuropathy and its precipitation by drugs or other factors have remained enigmatic partly because of the lack of an experimental model.
For these reasons, we have developed a mouse model of AIP by partially disrupting porphobilinogen deaminase (PBGD) by gene targeting (5). PBGD-deficient mice $\left(\mathrm{PBGD}^{-/}\right.$) recapitulate the drug-precipitated biochemical abnormalities of acute porphyria in humans and develop some neuropathological features resembling those of patients with the inherited disease. This experimental model should allow testing of various hypotheses proposed as possible mechanisms of porphyric neuropathy, including neurotoxicity of $\delta$-aminolevulinic acid (ALA) and heme deficiency in nervous tissues $(4,6)$.

A number of clinical observations associate ALA with acute porphyria. Thus, acute attacks, including motor neuropathy, invariably are accompanied by increased activity of hepatic ALA synthase and increased plasma levels and urinary excretion of ALA $(1,3)$. Treatments considered effective, such as high carbohydrate intake or heme infusion, lower ALA excretion (7). Moreover, in tyrosinemia type I and acute lead poisoning, urinary ALA excretion is increased; in both conditions, symptoms resembling those of acute porphyria, such as abdominal pain and peripheral neuropathy, occur. ALA exerts a number of effects in bio- 
logical systems in vitro, including interactions with $\gamma$ aminobutyric acid (GABA) receptors (8) and free radical formation (9). However, many of these effects occur at relatively high concentrations that are unlikely to exist in tissues during acute attacks. Arguments against the ALA hypothesis are the high excretion of ALA in many asymptomatic patients and the lack of clinical signs of neurological dysfunction after ALA administration in healthy volunteers or patients with acute porphyria (reviewed in ref. 4). Extensive studies in rodents involving oral and parenteral administration of ALA for up to several weeks also failed to produce significant toxic, behavioral, or pharmacological effects (10). However, ALA given in the setting of normally regulated heme synthesis (i.e., without partial deficiency of a specific enzyme) may not reflect the pathophysiological situation of porphyria. Therefore, the question whether ALA can produce some, or even all, of the manifestations of acute porphyria has remained a controversial issue. Connected with this uncertainty is the unresolved question regarding actual ALA concentrations in the central and peripheral nervous systems or to what extent ALA overproduced in the liver may cross the blood-brain barrier (11).

In the present study, we have used behavioral tests, light and electron microscopy, and electrophysiological techniques to examine the development of peripheral neuropathy of $\mathrm{PBGD}^{-/-}$mice of different ages. Our data document a chronic and progressive axonal motor neuropathy that morphologically resembles the neuropathy of porphyria patients. Further experiments were carried out to determine the concentration of ALA in brain and peripheral tissue in $\mathrm{PBGD}^{-/-}$mice. Our data reveal that the motor neuropathy in $\mathrm{PBGD}^{-/-}$mice develops at normal or only slightly increased ALA concentration, making neurotoxicity of ALA an unlikely mechanism of porphyric neuropathy.

\section{Methods}

Animals and treatments. PBGD-deficient mice used in this study have previously been described (5). PBGD was partially inactivated by gene targeting so that one allele of PBGD had a loss of function disruption and the other allele a partial disruption. Compound heterozygous mice (designated PBGD-deficient, or $\mathrm{PBGD}^{-/-}$) have $25-30 \%$ of normal PBGD activity. Age- and gender-matched normal C57BL/ 6 wild-type $(+/+)$ mice were used

\section{Table 1}

Motor coordination and muscular performance in female mice

\begin{tabular}{|c|c|c|c|c|}
\hline \multirow[b]{2}{*}{ Test } & \multirow[b]{2}{*}{ Mouse } & \multicolumn{3}{|c|}{ Age (months) } \\
\hline & & 3 & 6 & 16 \\
\hline $\begin{array}{l}\text { Rotorod } \\
\text { (s) }\end{array}$ & $\begin{array}{l}\text { PBGD }^{-/-} \\
\text {control }\end{array}$ & $\begin{array}{c}151.2 \pm 29.3 \\
180^{\mathrm{B}}\end{array}$ & $\begin{array}{r}35.2 \pm 21.5^{\mathrm{A}} \\
161.4 \pm 11.8\end{array}$ & $\begin{array}{c}1.2 \pm 0.4^{\mathrm{A}} \\
163.6 \pm 16.4\end{array}$ \\
\hline $\begin{array}{l}\text { Walk on rod } \\
\text { (s) }\end{array}$ & $\begin{array}{l}\mathrm{PBGD}^{-/-} \\
\text {control }\end{array}$ & $\begin{array}{l}3.0 \pm 0.5 \\
2.2 \pm 0.2\end{array}$ & $\begin{array}{l}4.2 \pm 0.8 \\
1.8 \pm 0.4\end{array}$ & $\begin{array}{c}51.8 \pm 8.3^{\mathrm{A}} \\
4.2 \pm 0.4\end{array}$ \\
\hline $\begin{array}{l}\text { Inclined plane } \\
\left({ }^{\circ}\right)\end{array}$ & $\begin{array}{l}\text { PBGD }^{-/-} \\
\text {control }\end{array}$ & $\begin{array}{l}80.2 \pm 2.2 \\
88.4 \pm 5.0\end{array}$ & $\begin{array}{l}78.6 \pm 2.6^{C} \\
86.2 \pm 1.0\end{array}$ & $\begin{array}{l}67.4 \pm 4.5^{\mathrm{D}} \\
78.8 \pm 2.0\end{array}$ \\
\hline $\begin{array}{l}\text { Escape reaction } \\
\text { (s) }\end{array}$ & $\begin{array}{l}\text { PBGD }^{-/-} \\
\text {control }\end{array}$ & $\begin{array}{r}9.0 \pm 2.8 \\
10.0 \pm 1.1\end{array}$ & $\begin{array}{c}45^{\mathrm{A}, \mathrm{E}} \\
3.0 \pm 0.7\end{array}$ & $\begin{array}{c}45^{\mathrm{A}, \mathrm{E}} \\
6.8 \pm 1.4\end{array}$ \\
\hline $\begin{array}{l}\text { Muscular endurance } \\
\text { (s) }\end{array}$ & $\begin{array}{l}\text { PBGD }^{-/-} \\
\text {control }\end{array}$ & $\begin{array}{l}51.8 \pm 4.0 \\
56.8 \pm 2.0\end{array}$ & $\begin{array}{l}40.2 \pm 9.1 \\
46.6 \pm 8.5\end{array}$ & $\begin{array}{c}32.8 \pm 8.0^{\mathrm{D}} \\
57.2 \pm 2.9\end{array}$ \\
\hline $\begin{array}{l}\text { Maximal strength } \\
(\mathrm{N})\end{array}$ & $\begin{array}{l}\mathrm{PBGD}^{-/-} \\
\text {control }\end{array}$ & $\begin{array}{l}0.025 \pm 0.002 \\
0.028 \pm 0.002\end{array}$ & $\begin{array}{l}0.018 \pm 0.002^{C} \\
0.023 \pm 0.002\end{array}$ & $\begin{array}{l}0.012 \pm 0.002^{\mathrm{A}} \\
0.023 \pm 0.004\end{array}$ \\
\hline
\end{tabular}

Data represent mean \pm SEM $(n=5)$. $\mathrm{PBGD}^{-/-}$mice are compared with age-matched wild-type control mice. ${ }^{A} P<0.001 .{ }^{B} 180 \mathrm{~s}$, time limit of the test. ${ }^{C} P<0.01 .{ }^{D} P<0.05$. ${ }^{E} 45 \mathrm{~s}$, time limit of the test. as controls. Mice were maintained in a 12-hour light/12-hour dark cycle and had free access to standard rodent laboratory chow and drinking water. The animals were studied at various ages: old (15.5-20.5 months), middle (six months), and young (two to three months). To biochemically imitate a human porphyric attack, mice were treated with increasing doses (100, 110,120 , and $125 \mathrm{mg} / \mathrm{kg}$ ) of phenobarbital intraperitoneally for four consecutive days (5).

Behavioral studies. Standard behavioral tests were selected to evaluate motor function in $\mathrm{PBGD}^{-/-}$mice (12). The rotorod test measures motor coordination and proprioceptive sensitivity. It determines the time (in seconds) that mice can stay on a rotating dowel turning at $12 \mathrm{rpm}$. In addition, the motor coordination was studied on an inclined plane, where the angle at which mice can no longer remain on the plane is determined. The walk-on-a-rod test evaluates the time required (in seconds) to cross a $40-\mathrm{cm}$-long rod $10 \mathrm{~mm}$ in diameter. The hot plate test examines the escape reaction: the time (in seconds) that elapses until the mouse jumps out of a glass cylinder $(17 \mathrm{~cm}$ high and $9 \mathrm{~cm}$ in diameter) with the base plate at $48^{\circ} \mathrm{C}$. Muscular endurance was quantified by determination of the time (in seconds) an animal keeps hold of a weight (32 g) with two of its legs when lifted by the tail. Maximal strength (in newtons) was measured with the mouse pulling a piece of wire connected to an isometric transducer. Pain threshold was determined by the tail-flick test and the occurrence of the paw-lick response during hot plate tests. In the tail-flick test, an intense light beam is focused on the tail, and the time (in seconds) that passes until the animal flicks its tail is determined.

Light and electron microscopy. The femoral nerve (comprising branches of the quadriceps muscle and the cutaneous saphenous nerve) was processed for light and electron microscopy as recently described $(13,14)$. Snap-frozen and unfixed cryosections $(6 \mu \mathrm{m})$ were subjected to indirect immunoperoxidase staining with antibodies against the myelin-specific protein zero $\left(\mathrm{P}_{0}\right)\left(\mathrm{P}_{0}, \mathrm{mAb}\right.$ anti- $\mathrm{P}_{0}$, clone D41E4 provided by S.L. Miller, Children's Hospital, Philadelphia, Pennsylvania, USA; ref. 15) and against the glial fibrillary acidic protein (GFAP) (GFAP, polyclonal rabbit anti-GFAP purchased from DAKO A/S, Golstrup, Denmark) and included negative controls for the secondary peroxidase-labeled antibodies (goat anti-mouse IgG [Fc] $\mathrm{P}_{0}-\mathrm{Ab}$ and goat anti-rabbit IgG [whole molecule] $\mathrm{P}_{0}-\mathrm{Ab}$; Sigma Chemical Co., St. Louis, Missouri, USA). Counts of myelinated axons were performed on micrographs of toluidine blue-stained semi-thin plastic sections $(1 \mu \mathrm{m})$ of the quadriceps muscle branch of the femoral nerve at a final magnification of $\times 800$.

Electrophysiology. Investigation of nerve conduction characteristics of facial and sciatic nerves in 21 (15.5-20.5 months old) $\mathrm{PBGD}^{-/-}$mice and 16 gender- and age-matched control mice were performed with methods described previously (16). Electromyography in five $\mathrm{PBGD}^{-/}$and four control mice was done with a Tönnies digital electromyograph (Tönnies, Würzburg, Germany) with a concentric needle electrode. Motor unit action potentials (MUAPs) were elicited by gently pressing on the opposite limb to induce a withdrawal response. Microdialysis and ALA measurements. Microdialysis (17) allows continuous monitoring of substances from the extracellular space in tissues and organs in vivo with minimal perturbation of the physiological system, i.e., without contamination by blood. The microdialysis probe (CMA12; shaft length $6 \mathrm{~mm}$, diameter $0.5 \mathrm{~mm}$, membrane length $2 \mathrm{~mm}$, pore size $20 \mathrm{kDa}$; Carnegie Medicine AB, Stockholm, Sweden) was placed by a stereotaxic device into the striatum to estimate central nervous system concen- 
trations. In other experiments, the probe was placed close to the tibial nerve of the hindleg to derive peripheral tissue concentrations. Samples of extracellular fluid (ECF) were collected, and ALA levels in the ECF of striatum and peripheral tissue, as well as in blood and urine, were analyzed with an HPLC method (18).

Statistical analysis. Differences in the number of myelinated axons of the femoral nerve were analyzed by using Student's $t$ test. The double-sided U test (InStat; GraphPad Software for Science Inc., San Diego, California, USA) was applied to electrophysiological and electromyographical data. Behavioral tests were analyzed by ANOVA combined with the Scheffé post hoc test.

\section{Results}

Behavioral studies of motor function. Motor dysfunction was evident in all behavioral tests (Table 1) in old PBGD-/mice (age 16 months) compared with age-matched controls. In particular, in the rotorod test, old $\mathrm{PBGD}^{-/-}$mice were unable to stay on the turning rod and unable to escape from a cylinder placed on a hot plate (escape reaction). Motor disturbance was already demonstrable at six months for the rotorod, inclined plane, and maximal strength tests, as well as for the escape reaction, but for three-month-old mice the differences were not statistically significant.

Sensory deficits were not obvious in $\mathrm{PBGD}^{-/-}$mice of any age. Thus, pain threshold, measured with tail-flick or pawlick response during a hot plate test, was not different in $\mathrm{PBGD}^{-/}$and control mice (data not shown).

Light microscopy and immunohistochemistry of peripheral nerves. The most striking finding in quadriceps nerves from $17-$ month-old $\mathrm{PBGD}^{-/-}$mice was a reduction in the number of large axons (diameter $>8 \mu \mathrm{m}$ ). These large axons decreased by 90\% (from 139 to 14; Figure 1, e-g). The overall diameter of all quadriceps nerves investigated also was strongly reduced in old $\mathrm{PBGD}^{-/-}$mice. At six months of age, the reduction of large-caliber axons was $\sim 60 \%$ (from 141 to 53; Figure 1, c, d, and g). At this age, extended regions of the endoneurium were occupied by cellular profiles that were devoid of myelin (Figure 1d). Contorted myelin and myelin ovoids were also observed, indicating degenerative events. In quadriceps nerves from two-month-old $\mathrm{PBGD}^{-/-}$mice, neither loss of large-caliber axons nor myelin profiles suggesting degeneration were observed (Figure 1, a, b, and g). Immunohistochemistry with antibodies against the myelin component $\mathrm{P}_{0}$ confirmed the light microscopy findings in aged mice (Figure 2, $\mathrm{a}$ and c). A prominent feature was the increased expression of GFAP, an established marker of nonmyelinating and denervated Schwann cells (Figure 2).

Electron microscopy. Striking ultrastructural abnormalities were found in quadriceps nerves in $\mathrm{PBGD}^{-/-}$mice six and 17 months old. In addition to the reduced numbers of large-caliber fibers, the presence of basal lamina-covered Schwann cell profiles devoid of axons and myelin was the most frequent pathological alteration (Figure 3, a and b). These structures represent most probably denervated Schwann cells (bands of Büngner) and were often situated close to axon-Schwann cell units with normally shaped or thin myelin (Figure 3a). The bands of Büngner were occasionally associated with axonal growth cones (Figure $3 \mathrm{c}$ ) or with nonmyelinated small-caliber axons (Figure 3d).

Another striking characteristic was the presence of myelinated axons with features suggesting axonal degeneration, such as overall high electron density, disorganized neurofilaments and neurotubules, and clusters of electron-dense material apposed to the axolemma (Figure 4, $\mathrm{a}$ and b). Axonal membranes were often discontinuous, and the periaxonal compartment often was poorly defined (Figure 4b). Absence of axonal mitochondria (Figure 4, a and b) was also frequently observed. Another typical feature was the occurrence of myelin-containing Schwann cells that were devoid of an axon and characterized by a contorted myelin structure reminiscent of Wallerian degeneration (Figure 4, c and d). Approximately $5-10 \%$ of myelinated axon-Schwann cell units exhibited the described degenerative phenotype.

Nonmyelinating Schwann cells ensheathing bundles of small-caliber axons were also abnormally organized in the quadriceps nerve of six- and 17-month-old mice, as

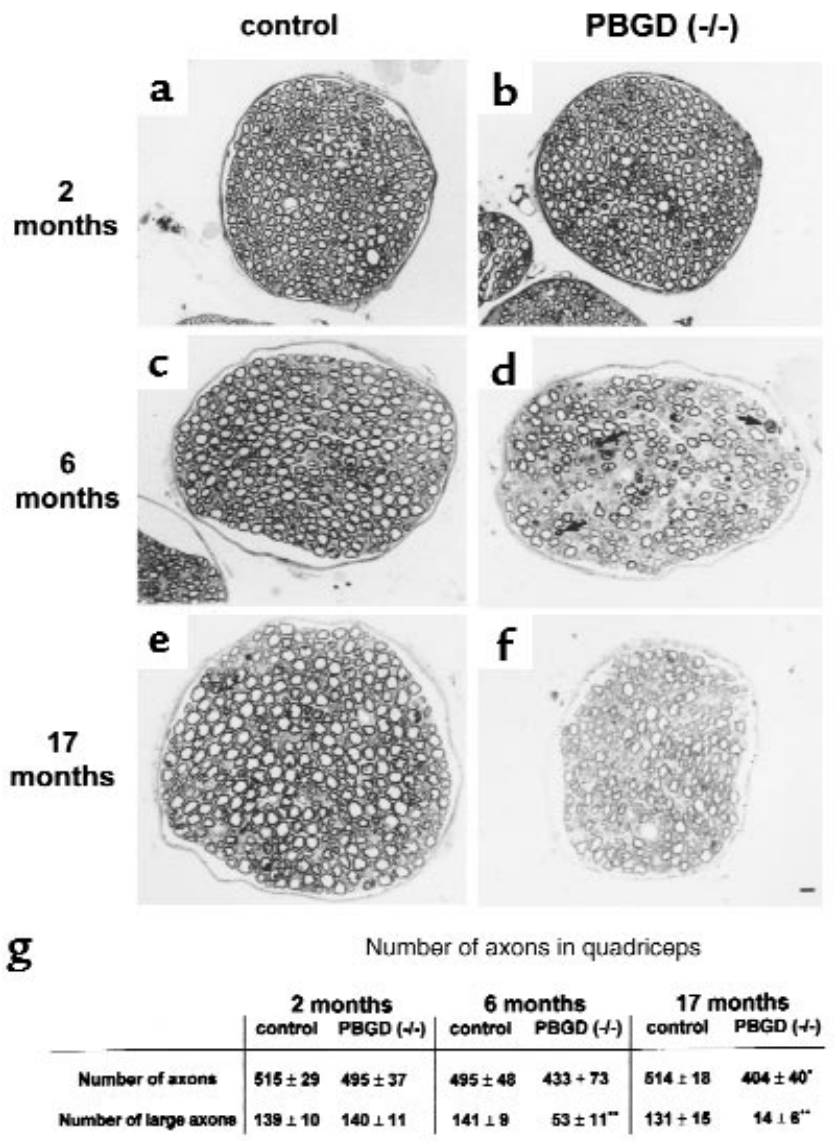

Figure 1

Light micrographs of semi-thin plastic sections of femoral quadriceps nerves of control (a, c, and $\mathbf{e})$ and $\mathrm{PBGD}^{-/-}(\mathbf{b}, \mathbf{d}$, and $\mathbf{f})$ mice at two months ( $\mathbf{a}$ and $\left.\mathbf{b}\right)$, six months (c and $\mathbf{d}$ ), and 17 months (e and $\mathbf{f}$ ) of age. (g) Number of axons in quadriceps nerves. Numbers represent mean values from three mice $\pm S D$. Largest axons were thicker than $5 \mu \mathrm{m}$ in two-month-old mice and thicker than $8 \mu \mathrm{m}$ in six- and 17 -month-old mice. *Significantly different compared with control mice $(P<0.05)$. * Significantly different compared with control mice $(P<0.01)$. (a and $\mathbf{b})$ At two months of age, there are no pathological alterations in femoral quadriceps nerves of $\mathrm{PBGD}^{-/-}$mice. (c and $\left.\mathbf{d}\right)$ At six months of age, quadriceps nerves from $\mathrm{PBGD}^{-/-}$mice are characterized by a significant loss of axonal profiles of larger caliber. In addition, abnormal myelin profiles (arrows) and extended regions not occupied by myelinated fibers are typical findings. (e and f) At 17 months of age, the overall diameter of the femoral nerve and the number of axonal profiles of larger caliber is strongly reduced. Scale bar: $10 \mu \mathrm{m}$. 
reflected by slender cell processes protruding into the endoneurial space (Figure 4e). By contrast, both myelinated and nonmyelinated fibers appeared normal in the saphenous nerve, the major sensory cutaneous branch of the femoral nerve (Figure 4f).

In summary, the morphological findings are consistent with degeneration of large-caliber axons, secondary Schwann cell reactions, and axonal regeneration.

Electrophysiological investigations. We found a statistically significant decrease of the sciatic nerve motor response (M-response) amplitude in $\mathrm{PBGD}^{-/}$mice (Figure $5 \mathrm{a}$ ). All other sciatic nerve conduction studies were normal in the $\mathrm{PBGD}^{-/-}$mice compared with control mice (Table 2). The shape of the M-response was usually biphasic or triphasic. Slight temporal dispersion occurred in five $\mathrm{PBGD}^{-/-}$mice but in only one control mouse (Figure 5a). Four out of the five PBGD ${ }^{-/}$mice with temporal dispersion had low M-response amplitudes $(<10 \mathrm{mV})$. However, very low M-response amplitudes also occurred in six $\mathrm{PBGD}^{-/-}$mice and two control

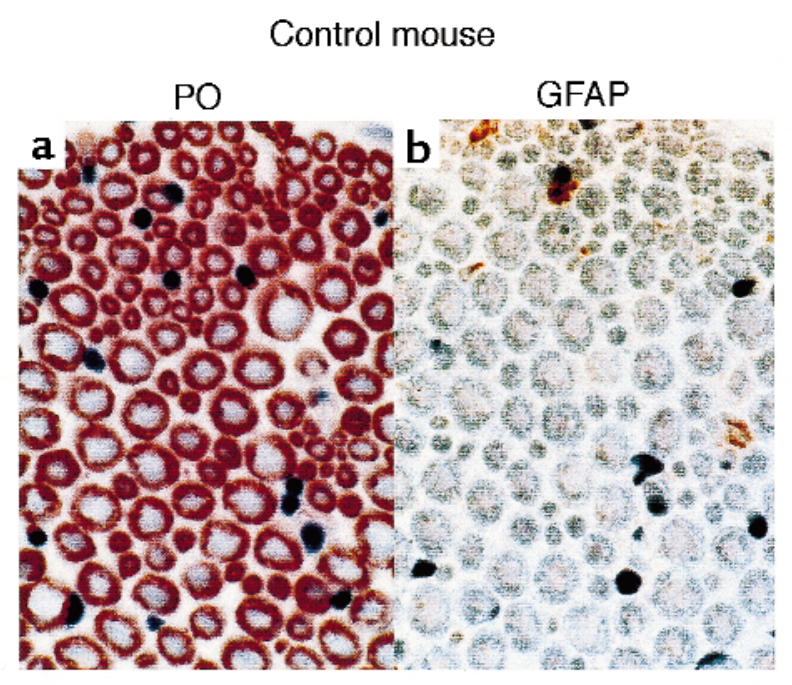

PBGD (-/-) mouse

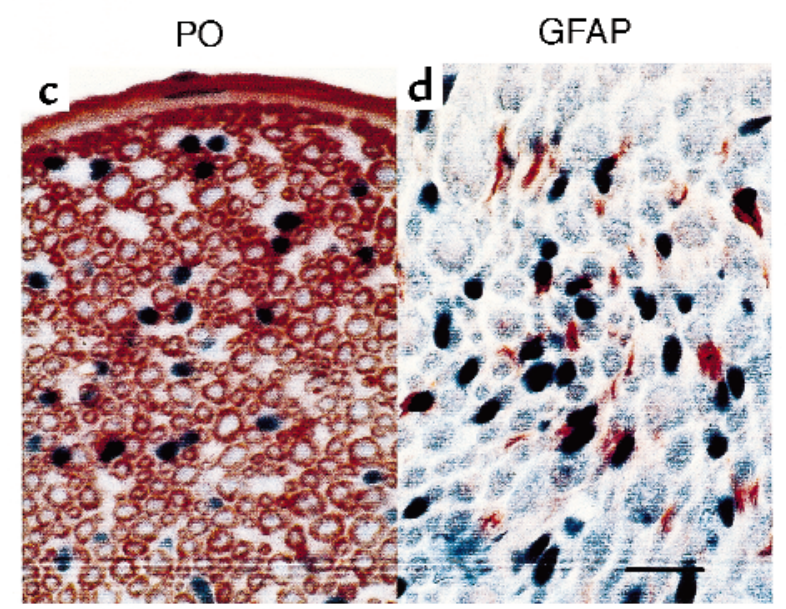

Figure 2

Immunostaining of myelin with antibodies against $\mathrm{P}_{0}$ (red color) and GFAP (red color). Cryosections of the femoral nerve of a control mouse (a and $\mathbf{b})$ and a mouse with PBGD deficiency ( $\mathbf{c}$ and $\mathbf{d}$ ), both at 16 months of age. Scale bar: $20 \mu \mathrm{m}$. mice with no temporal dispersion. Mixed-afferent nerve conduction was normal in the sciatic nerve of $\mathrm{PBGD}^{-/-}$ mice (Table 2). Facial nerve motor conduction studies, including the absolute refractory time, were normal in $\mathrm{PBGD}^{-/-}$mice (data not shown).

Electromyography studies were performed with the greater gluteal muscle, the quadriceps, and the gastrocnemius muscle in control and $\mathrm{PBGD}^{-/-}$mice. Our main finding was a significant increase of MUAP amplitudes in all investigated muscles of $\mathrm{PBGD}^{-/}$mice (Table 2 and Figure 5c). The short duration of MUAPs and the rapid recruitment of muscle units precluded a detailed analysis of single MUAP duration. We detected polyphasic MUAPs in three out of five $\mathrm{PBGD}^{-/}$mice (all in the greater gluteal muscle, three out of 93 MUAPs analyzed; Figure 5b), fibrillation in one $\mathrm{PBGD}^{-/-}$mouse (quadriceps muscle), and fasciculations in the greater gluteal and quadriceps muscles of one $\mathrm{PBGD}^{-/-}$mouse. These observations are likely to underestimate the true degree of abnormality because of the high background activity. No pathological spontaneous activity occurred in control mice. The recruitment pattern consisted of normal-appearing recruitment of MUAPs with an amplitude of $250-1,000 \mu \mathrm{V}$, with an interference pattern on maximal withdrawal in control mice. In $\mathrm{PBGD}^{-/-}$mice, however, early recruitment of highamplitude MUAPs occurred on muscle contraction, and no dense interference pattern was obtained (Figure 5c). Also, the discharge frequency of motor units was slightly higher in $\mathrm{PBGD}^{-/-}$mice (range $30-140 \mathrm{~Hz}$ ) compared with control mice (range 14-70 Hz).

These findings are characteristic of a chronic axonopathy predominantly affecting motor fibers. There is no electrophysiological evidence for primary demyelination or sensory nerve involvement.

ALA concentrations. Only a slight increase (approximately twofold) in the plasma concentration and urinary excretion of ALA was observed in $\mathrm{PBGD}^{-/-}$mice (Table 3). In ECF near the tibial nerve of hindlimbs, ALA concentrations were determined to be $\sim 15-25 \%$ of the plasma levels in both $\mathrm{PBGD}^{-/-}$and control mice. In striatum of $\mathrm{PBGD}^{-/}$ and control mice, ALA was undetectable without drug administration. Drugs such as phenobarbital induce ALA synthase in the liver and precipitate acute attacks of porphyria. We therefore treated mice with phenobarbital to increase the concentration of plasma ALA to levels observed in patients during acute attacks of porphyria $\left(2-13 \times 10^{-6} \mathrm{M}\right.$; Table 3) (11). As expected, phenobarbital treatment caused a massive ( $\sim 50$-fold) increase of ALA in plasma in $\mathrm{PBGD}^{-/-}$mice, whereas the increase in controls was only twofold (Table 3). Under these conditions, the brain (striatum) ECF concentration of ALA rose from undetectable to $\sim 6 \times 10^{-8} \mathrm{M}$ in $\mathrm{PBGD}^{-/-}$mice and from undetectable to $\sim 2 \times 10^{-9} \mathrm{M}$ in controls. The plasma-tobrain ratio of 120:1 and 250:1 suggests a high blood-brain barrier for ALA. Of special interest in this investigation is the fact that $\mathrm{PBGD}^{-/-}$mice developed motor neuropathy without any drug treatment.

\section{Discussion}

$\mathrm{PBGD}^{-/-}$mice develop progressive muscle weakness and loss of motor coordination with increasing age, as evidenced in behavioral tests. The disturbance of motor 

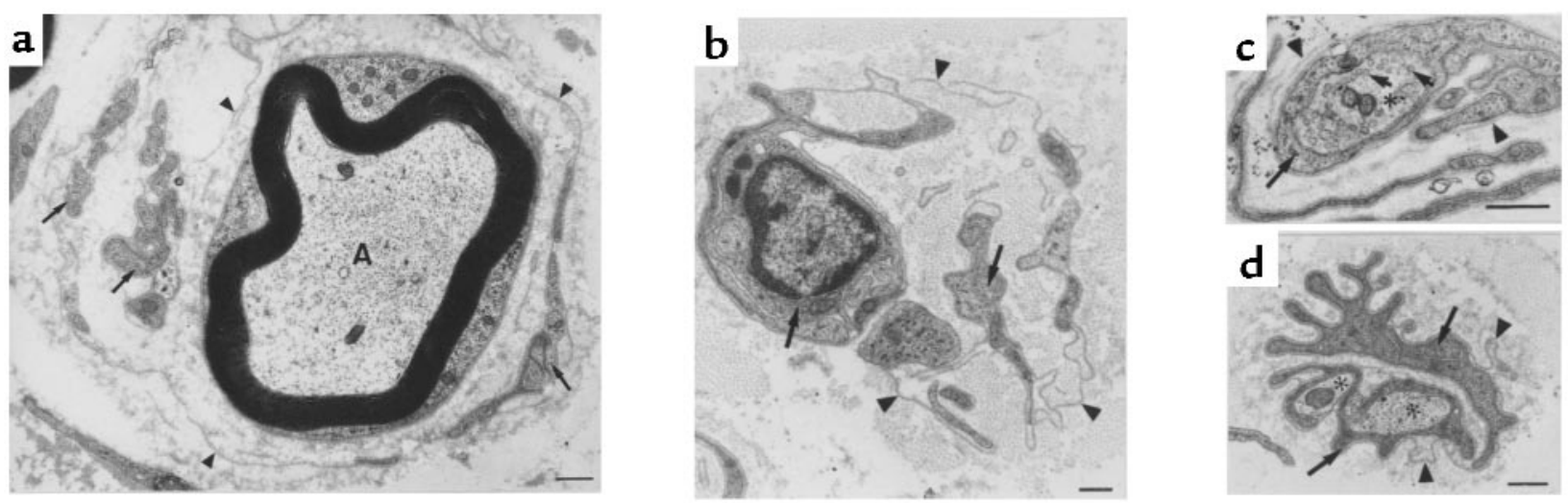

Figure 3

Electron microscopy of pathological alterations of quadriceps nerves in six-month-old PBGD ina-covered Schwann cell profiles (arrows) reminiscent of bands of Büngner. Arrowheads point to empty basal laminae. (b) Schwann cells devoid of axon and myelin (arrows) form profiles reminiscent of bands of Büngner. Arrowheads point to Schwann cell basal laminae. (c) This axonal profile (asterisk) containing numerous vesicles (small arrows) is reminiscent of a growth cone usually found in injured nerves. Note the close association with a Schwann cell (large arrows). Arrowheads point to Schwann cell basal laminae. (d) Two small-caliber axons (asterisks), probably axonal sprouts, are in close association with a Schwann cell profile (arrows) reminiscent of a band of Büngner. Arrowheads point to Schwann cell basal laminae. Scale bars: $0.5 \mu \mathrm{m}$

function is most likely caused by a continuous decrease in the number of larger-caliber axons in motor nerves, with a reduction of $60 \%$ and $90 \%$ at six and 17 months of age, respectively (Figures 1 and 2). The predominant affliction of the larger-caliber axons has also been noted in the few nerve biopsies performed in patients with porphyric peripheral neuropathy $(6,19)$. Apparently, degenerated axons have the ability to regenerate. The observation that the loss of large-caliber axons is higher than the decrease in the total number of axons can be explained by the regrowth and remyelination of axons that acquire and maintain a small-caliber phenotype (Figure $1 \mathrm{~g}$ ). The increased GFAP staining in the peripheral nerves of $\mathrm{PBGD}^{-/}$mice (Figure 2, $\mathrm{b}$ and d) also is consistent with increased Schwann cell activity associated with regeneration of axons. A further argument in favor of axonal regrowth is the decreased recruitment and polyphasia of MUAPs in $\mathrm{PBGD}^{-/-}$mice. The increase of MUAP amplitudes also is consistent with enlargement of motor unit size due to reinnervation, as is the observation of axonal growth cones and axonal sprouts (Figure 3, c and d). Electromyographic findings in human porphyric neuropathy usually also reveal decreased recruitment of MUAPs shortly after onset of weakness $(20,21)$.

The conspicuous absence of pathological changes in the sensory saphenous nerve again matches the clinical experience in porphyria patients, as the peripheral neuropathy is chiefly a motor paralysis; sensory disturbances are minimal and late, if they appear at all $(2,4,6,22)$.

Our interpretation of the structural data is supported by the electrophysiological studies, including nerve conduction and electromyographic experiments in $\mathrm{PBGD}^{-/-}$mice. In particular, there were no signs of primary demyelination (temporal dispersion, slowing of nerve conduction, increase of latencies; Table 2 and
Figure 5). Mild admixed demyelination, indicated by mild temporal dispersion, occurred only in the most severely affected $\mathrm{PBGD}^{-/-}$mice with a very low $\mathrm{M}$-response. The most prominent electromyography (EMG) finding in $\mathrm{PBGD}^{-/-}$mice was a severe chronic neurogenic pattern with decreased MUAP recruitment, increased MUAP amplitudes, and polyphasia. Although we may not have achieved maximal innervation, we show that normal mice achieve a dense interference pattern under our experimental conditions, whereas $\mathrm{PBGD}^{-/-}$mice recruit highamplitude MUAPs relatively early without achieving a dense interference pattern. This is due to a loss of motor
Table 2

Nerve conduction and electromyography

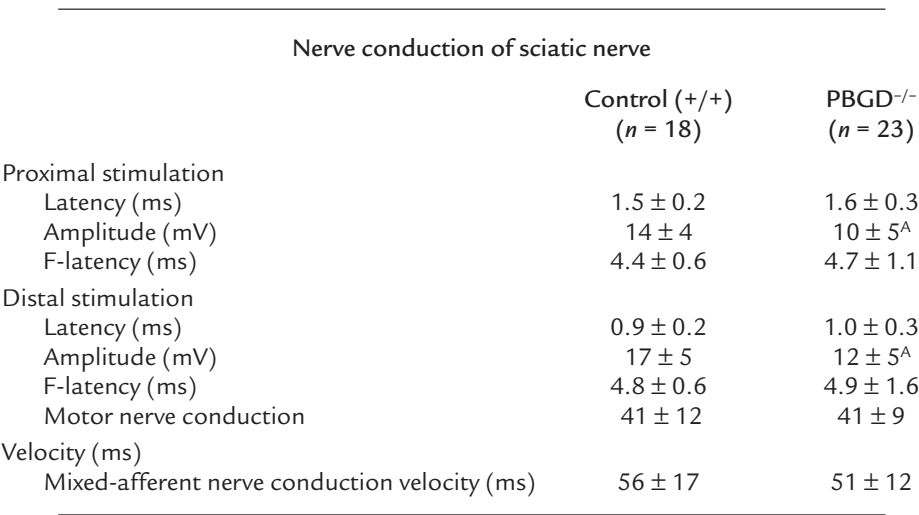

The data are expressed as mean \pm SD. ${ }^{A}$ Difference of means between control and $\mathrm{PBGD}^{-/-}$- mice; $P<0.05$, double-sided $\mathrm{U}$ test. Electromyography

Muscle

Gluteus maximus

Quadriceps

Gastrocnemius

\begin{tabular}{|c|c|c|c|}
\hline \multicolumn{4}{|c|}{ Electromyography } \\
\hline \multicolumn{2}{|c|}{$\begin{array}{c}\text { Control }(+/+) \\
(n=4)\end{array}$} & \multicolumn{2}{|c|}{$\begin{array}{l}\mathrm{PBGD}^{-/-} \\
(n=5)\end{array}$} \\
\hline $425 \mu \mathrm{V}^{\mathrm{B}}$ & $(100-3,000 ; n=50)$ & $960 \mu \mathrm{V}$ & $(200-6,000 ; n=93)$ \\
\hline $400 \mu \mathrm{V}^{\mathrm{B}}$ & $(180-1,400 ; n=53)$ & $970 \mu \mathrm{V}$ & $(190-3,000 ; n=38)$ \\
\hline $390 \mu \mathrm{V}^{\mathrm{B}}$ & $(120-840 ; n=41)$ & $1,600 \mu \mathrm{V}$ & $(500-3,390 ; n=15)$ \\
\hline
\end{tabular}

The data are given as medians (range, number of motor units analyzed). ${ }^{\text {BThe differences of the }}$ medians between the control and $\mathrm{PBGD}^{-/-}$mice were significantly different in all three muscles; $P<0.05$, double-sided $\mathrm{U}$ test. 
units and corresponds to the lower compound muscle action potential (CMAP) amplitudes in the sciatic nerve conduction studies.

The results of these nerve conduction studies in $\mathrm{PBGD}^{-/-}$mice are consistent with electrophysiological findings in patients with porphyric neuropathy who suffer from an axonal neuropathy that predominantly affects motor fibers with little electrophysiological evidence of
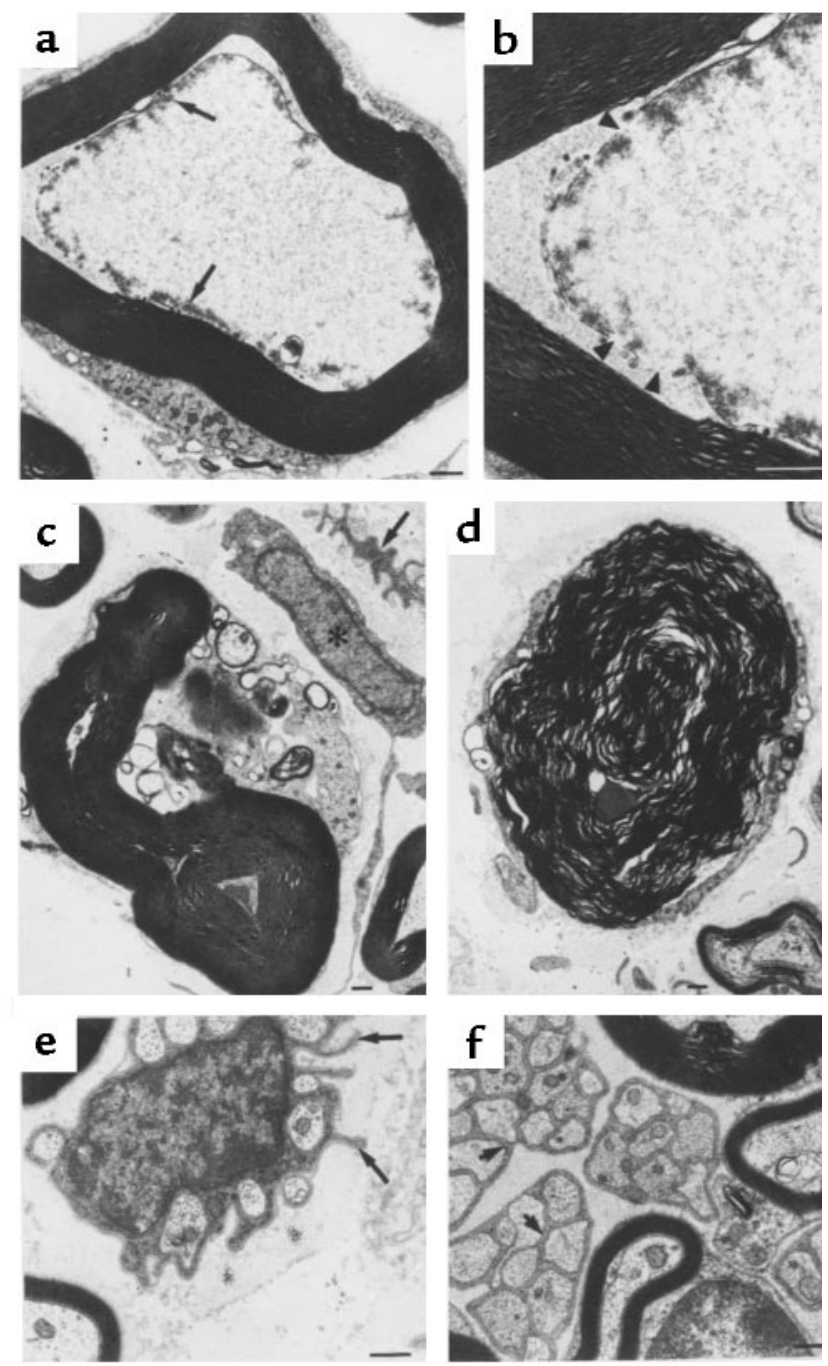

\section{Figure 4}

Electron microscopy of pathological features indicative of axon degeneration of quadriceps and saphenous nerves in six-month-old PBGD-/- mice. ( $\mathbf{a}$ and $\mathbf{b}$ ) The axon of this fiber is characterized by a complete disorganization of its cytoskeletal elements and by electron-dense material apposed to the axolemma (arrows in a). The high-power electron micrograph (b) reveals an interrupted axon membrane (arrowheads). The periaxonal compartment is poorly defined. ( $\mathbf{c}$ and $\mathbf{d}$ ) These fibers are characterized by axonal loss and a contortion of the remaining myelin profiles, a feature reminiscent of Wallerian degeneration. Note denervated Schwann cell reminiscent of a band of Büngner at the upper-right corner in c (arrow). Asterisk in $\mathbf{c}$ is on an endoneurial fibroblast. (e) In the quadriceps nerve, the Schwann cells form abnormal processes protruding into the endoneurial space (arrows). (f) The myelinated and nonmyelinated fibers of the saphenous nerve are not distinguishable from fibers of wild-type mice. Note the individual ensheathment of each axon by a process of the nonmyelinated Schwann cell (small arrows). Scale bars: $0.5 \mu \mathrm{m}$ demyelination $(6,20-22)$. EMG findings in human porphyric neuropathy usually reveal decreased recruitment of MUAPs shortly after onset of weakness, with pathological spontaneous activity first appearing in proximal muscles and later spreading to distal muscles $(20,21)$.

The behavioral, structural, and electrophysiological data in $\mathrm{PBGD}^{-/}$mice provide convincing evidence that porphyric neuropathy is primarily an axonal motor neuropathy and that the additional changes described most likely are the result of repeated events leading to degeneration and regeneration.

A number of hypotheses have been proposed to explain the pathogenesis of porphyric neuropathy, but none has been directly tested. Increased ALA synthase activity, accumulation of ALA, and heme deficiency in the liver are biochemical features common to all acute porphyrias. Explanations that link these biochemical changes to neuronal dysfunction implicate ALA as a neurotoxin and/or propose decreased functions of specific hemeproteins. The almost invariable association of clinical symptoms with high levels of ALA in serum and urine and the demonstration of in vitro effects of ALA in neurophysiological test systems, albeit usually observed at concentrations unlikely to occur in acute porphyria, led to the prevailing consideration of ALA as a neurotoxin. However, the results reported here reveal that highly increased ALA levels are not a prerequisite for peripheral neuropathy, as mice developed progressive neuropathology without high levels of ALA. Rather, the data suggest that heme deficiency in the liver or nervous system could lead to decreased levels of key hemeproteins such as mitochondrial cytochromes, tryptophan dioxygenase, nitric oxide synthase, or soluble guanylate cyclase in various tissues, resulting in indirect or direct effects in motor neurons.

Preliminary investigations of a number of hemeproteins support this possibility. Thus, mitochondria isolated from liver of $\mathrm{PBGD}^{-/-}$mice displayed decreased oxygen consumption presumably due to decreased function of hemeproteins of the respiratory chain, and tryptophan levels were elevated in the brain of $\mathrm{PBGD}^{-/-}$mice, although only after phenobarbital treatment (Lindberg, R.L.P., et al., unpublished observations), similar to studies reported by Litman and Correia (23) in a model of chemically induced porphyria in rats. On the other hand, extensive studies in our laboratory of heme-dependent dimerization, enzymatic activity, and induction of neuronal nitric oxide synthase did not reveal differences between $\mathrm{PBGD}^{-/-}$mice and controls (Lindberg, R.L.P., and Meyer, U.A., unpublished observations). Thus, the role of heme deficiency and its differential effects on various hemeproteins in the generation of porphyric neuropathy require further study.

Many patients carrying the specific enzyme defects of acute porphyrias have no clinical symptoms. Clinical manifestations reflecting neuropathy frequently are precipitated by drugs, hormones, and fasting. These factors are known to induce or increase the inducibility of hepatic ALA synthase $(1,2,6)$. After an acute attack, most symptoms are reversible.

However, in the animal model of acute porphyria described here, the neuropathy developed progressively with age and in the absence of high levels of ALA. In 
Table 3

ALA concentrations in $\mathrm{PBGD}^{-/-}$and control mice, and in patients with acute intermittent porphyria

\begin{tabular}{|c|c|c|c|c|c|}
\hline & Genotype & $\begin{array}{c}\text { Plasma } \\
(\mu \mathrm{M})\end{array}$ & $\begin{array}{c}\text { Urine } \\
(\mu \mathrm{mol} / \mu \mathrm{mol} \text { creatinine })\end{array}$ & $\begin{array}{l}\text { Striatum } \\
(\mathrm{nM})\end{array}$ & $\begin{array}{l}\text { Peripheral tissue }{ }^{A} \\
(\mu \mathrm{M})\end{array}$ \\
\hline No treatment & $\mathrm{PBGD}^{-/-}$ & $0.27 \pm 0.15(n=35)^{\mathrm{B}}$ & $0.034 \pm 0.015(n=42)^{\mathrm{B}}$ & ND & NA \\
\hline No treatment & Control $(+/+)$ & $0.12 \pm 0.07(n=23)$ & $0.019 \pm 0.003(n=36)$ & ND & $\begin{array}{c}0.03 \pm 0.02 \\
(n=4)\end{array}$ \\
\hline \multirow{3}{*}{$\begin{array}{l}\text { Phenobarbital } \\
\text { Phenobarbital }\end{array}$} & $\mathrm{PBGD}^{-/-}$ & $14.01 \pm 8.90(n=33)^{\mathrm{B}}$ & $1.159 \pm 0.741(n=17)^{\mathrm{B}}$ & $56.01 \pm 39.86(n=7)$ & $1.92(n=2)$ \\
\hline & Control $(+/+)$ & $0.28 \pm 0.10(n=32)$ & $0.019 \pm 0.013(n=30)$ & $2.36 \pm 0.89(n=6)$ & $0.05(n=1)$ \\
\hline & $\begin{array}{l}\text { Plasma } \\
(\mu \mathrm{M})\end{array}$ & $\begin{array}{c}\text { Urine } \\
(\mu \mathrm{mol} / \mu \mathrm{mol} \text { creatinine })\end{array}$ & $\begin{array}{l}\text { CSF } \\
(\mu \mathrm{M})\end{array}$ & & \\
\hline
\end{tabular}

AIP patients, symptomatic Normal
$1.8-13$ (refs. 11, 26; range, $n=34$ ) 0.005-0.164 (ref. 27) 0.027-2.1 (refs. 7, 11, 28, 29; range, $n=4$ ) $0.1 \pm 0.04(n=89)$
$<0.004$ (ref. 27)

Data are given as mean $\pm \mathrm{SD}$, except where indicated. $\mathrm{PBGD}^{-/-}$mice are compared with age-matched control mice. Mice were treated with phenobarbital intraperitoneally daily on four consecutive days with increasing doses $\left(100,110,120\right.$, and $125 \mathrm{mg} / \mathrm{kg}$ ); data represent combined values at 36 and $60 \mathrm{~h}$ after phenobarbital treatment. ${ }^{A} T$ he microdialysis probe was placed near the tibial nerve of the hindleg. ${ }^{\mathrm{B}} \mathrm{P}<0.001$. CSF, cerebrospinal fluid; $N A$, not analyzed; ND, not detectable.

$\mathrm{PBGD}^{-/-}$mice, therefore, axonal neuropathy most likely develops as a consequence of subacute or chronic heme deficiency. Mild chronic peripheral neuropathy was also documented by Mustajoki and Seppäläinen (24) in patients with latent porphyria, even in patients who never had acute symptoms, by decreased conduction velocity of slow motor fibers.

The animal model of acute porphyria described here thus shows similarities and differences to the human disease. For instance, although phenobarbital resulted in a massive induction of hepatic ALA synthase and consequent accumulation of plasma ALA to levels observed in patients during acute attacks (Table 3), mice did not manifest acute and reversible symptoms such as paralysis or seizures, and the motor disturbance was not visibly aggravated by the drug treatment. Moreover, there were no obvious signs of autonomic neuropathy such as tachycardia or a change in eating behavior in $\mathrm{PBGD}^{-/-}$mice, except for a slight but significant increase in blood pressure (Lindberg, R.L.P., unpublished observations).

The reasons for these discrepancies are unclear at this time. We consider it unlikely that the differences in phenotype are due to the lower activity of PBGD in mice $(\sim 30 \%$ of normal activity) compared with the $50 \%$ decrease in AIP patients. The $V_{\max }$ of PBGD in humans is normally about twice as high as the $\mathrm{V}_{\max }$ (uninduced) of ALA synthase (25), making it the second rate-limiting step. In C57BL/6 mice, however, we found the PBGD activity to be four to five times higher than that of ALA synthase. In our model, therefore, the enzyme deficiency was adjusted to the species difference between mouse and human liver to produce the same drug-induced biochemical changes in ALA synthase induction and ALA accumulation. Since acute porphyria shows extremely variable penetrance and expressivity, $\mathrm{PBGD}^{-/-} \mathrm{C} 57 \mathrm{BL} / 6$ mice may reflect only one of the possible phenotypes of the human disease.

In conclusion, we show that mice deficient in PBGD develop motor dysfunction and peripheral neuropathological features closely resembling those of patients with inherited acute porphyrias. The axonal neuropathy occurs in the absence of high levels of ALA. These data suggest that heme deficiency and consequent dysfunction of hemeproteins can cause porphyric neuropathy.
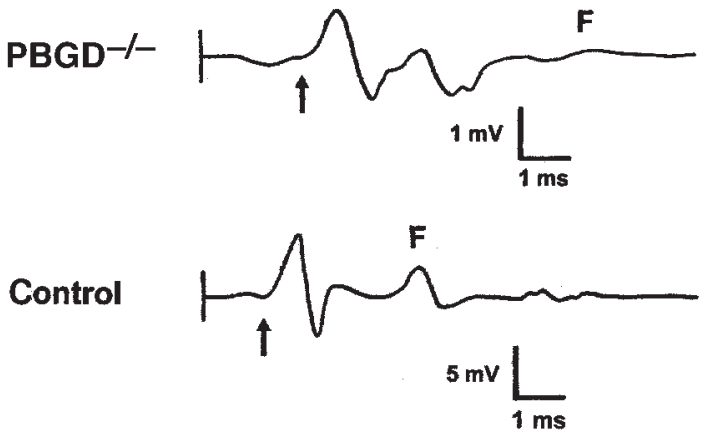

b

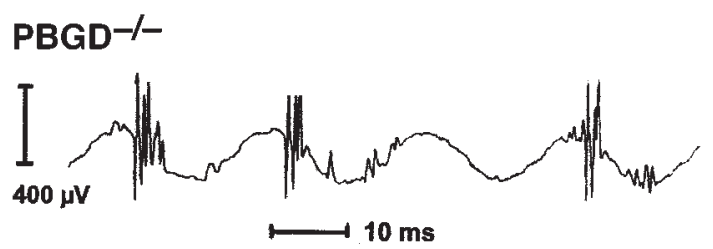

C
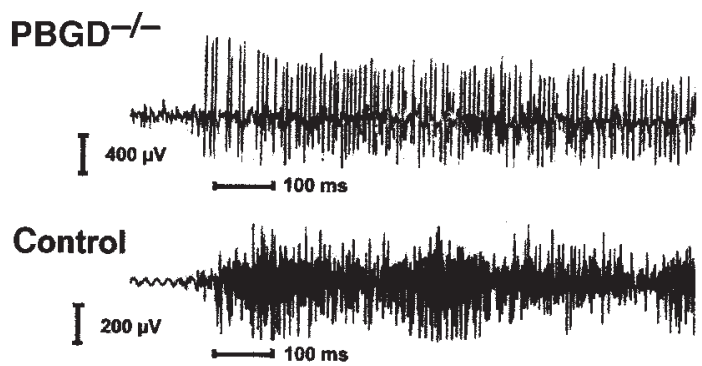

Figure 5

Neurophysiological abnormalities in $\mathrm{PBGD}^{-/-}$mice. (a) CMAP recordings from the foot muscles after proximal stimulation of the sciatic nerve. Note the different amplitude scales. $\mathrm{PBGD}^{-/-}$mouse and control were 16 months old. A decrease of the M-response amplitude and temporal dispersion can be seen in the $\mathrm{PBGD}^{-/-}$mouse. The arrow denotes the onset of the $\mathrm{M}$-response, and $\mathrm{F}$ represents $\mathrm{F}$-wave. Redrawn from original recordings. (b) Polyphasic MUAP recorded in the greater gluteal muscle of a $\mathrm{PBGD}^{-/-}$mouse. (c) Representative electromyography recordings from a $\mathrm{PBGD}^{-/-}$mouse (upper traces) and a control mouse (lower traces) during maximal withdrawal. Note the dense interference pattern in the control mouse, which was not achieved by the $\mathrm{PBGD}^{-/-}$mouse, and the higher MUAP amplitudes in the $\mathrm{PBGD}^{-/-}$mouse. 


\section{Acknowledgments}

We gratefully acknowledge C. Vodouhe for performing the behavior studies, as well as F. Hoffmann and M. Beer for expert technical assistance. This work was supported by the Swiss National Science Foundation, the Olga Mayenfish Foundation, and the Roche Research Foundation.

1. Kappas, A., Sassa, S., Galdbraith, R.A., and Nordmann, Y. 1989. The porphyrias. In The metabolic basis of inherited disease. C.R. Scriver, A.L. Beaudet, W.S. Sly, and D. Valle, editors. McGraw-Hill. New York, NY $1305-1365$

2. Windebank, A.J., and Bonkovsky, H.L. 1993. Porphyrical neuropathy. In Peripheric neuropathy. P.J. Dyck, P.K. Thomas, J.W. Griffin, P.A. Low, and J.F. Poduslo, editors. W.B. Saunders. Philadelphia, PA. 1161-1168.

3. Elder, G.H., Hift, R.J., and Meissner, P.N. 1997. The acute porphyrias. Lancet. 349:1613-1617.

4. Meyer, U.A., Schuurmans, M.M., and Lindberg, R.L.P. 1998. Acute porphyrias: pathogenesis of neurological manifestations. Semin. Liver Dis. 18:43-52

5. Lindberg, R.L.P., et al. 1996. Porphobilinogen deaminase deficiency in mice causes a neuropathy resembling that of human hepatic porphyria. Nat. Genet. 12:195-199.

6. Bonkovsky, H.L., and Schady, W. 1982. Neurologic manifestation of acute porphyria. Semin. Liver Dis. 2:108-124

7. Bonkovsky, H.L., et al. 1971. Repression of the overproduction of porphyrin precursors in acute intermittent porphyria by intravenous infusion of hematin. Proc. Natl. Acad. Sci. USA. 62:2725-2729.

8. Brennan, M.J.W., and Cantrill, R.C. 1979. $\delta$-aminolaevulinic acid is a potent agonist for GABA autoreceptors. Nature. 280:514-515.

9. Monteiro, H.P., Bechara, E.J.H., and Abdalla, D.S.P. 1991. Free radicals involvement in neurological porphyrias and lead poisoning. Mol. Cell. Biol. 103:73-83.

10. Edwards, S.R., Shanley, B.C., and Reynoldson, J.A. 1984. Neuropharmacology of delta-aminolaevulinic acid 1 . Effect of acute administration in rodents. Neuropharmacology. 23:477-481.

11. Gorchein, A., and Webber, R. 1987. $\delta$-aminolevulinic acid in plasma, cerebrospinal fluid, saliva and erythrocytes: studies in normal, uraemic and porphyric subjects. Clin. Sci. 72:103-112.

12. Tilson, H.A., and Mitchell, C.L. 1984. Neurobehavioral techniques to assess the effects of chemicals on the nervous system. Annu. Rev. Pharmacol. Toxicol. 24:425-450.

13. Anzini, P., et al. 1997. Structural abnormalities and deficient maintenance of peripheral nerve myelin in mice lacking the gap junction protein connexin 32. J. Neurosci. 17:4545-4551.
14. Carenini, S., Montag, D., Cremer, H., Schachner, M., and Martini, R. 1997. Absence of the myelin-associated glycoprotein (MAG) and the neural cell adhesion molecule (N-CAM) interferes with the maintenance but not with the formation of peripheral myelin. Cell Tissue Res. 287:3-9.

15. Miller, S.L., et al. 1984. Production and characterization of monoclonal antibodies to peripheral and central nervous system myelin. J. Neurochem. 43:394-400.

16. Zielasek, J., Martini, R., and Toyka, K.V. 1996. Functional abnormalities in P0-deficient mice resemble human hereditary neuropathies linked to P0 gene mutations. Muscle Nerve. 19:946-952.

17. Ungerstedt, U. 1991. Microdialysis-principles and applications for studies in animals and man. J. Intern. Med. 230:365-373.

18. Tomokuni, K., Ichiba, M., Hirai, Y., and Hasegawa, T. 1987. Optimized liquid-chromatographic method for fluorometric determination of urinary $\delta$-aminolevulinic acid in workers exposed to lead. Clin. Chem. 33:1665-1667.

19. Wakayama, Y., Muroga, T., Hibino, R., Matsui, T., and Utsumi, M. 1975. Peripheral nerve lesions in acute intermittent porphyria. Rinsho Shinkeigaku. 15:333-339.

20. Albers, J.W., Robertson, W.C., and Daube, J.R. 1978. Electrodiagnostic findings in acute porphyric neuropathy. Muscle Nerve. 1:292-296.

21. Flügel, K.A., and Druschky, K.F. 1977. Electromyogram and nerve condition in patients with acute intermittent porphyria.J. Neurol. 214:267-279.

22. Cavanagh, J.B., and Mellick, R.S. 1965. On the nature of peripheral nerve lesions associated with acute intermittent porphyria.J. Neurol. Neurosurg. Psychiatry. 28:320-327.

23. Litman, D.A., and Correia, M.A. 1983. L-tryptophan: a common denominator of biochemical and neurological events of acute hepatic porphyria. Science. 222:1031-1033.

24. Mustajoki, P., and Seppäläinen, A.M. 1975. Neuropathy in latent hereditary hepatic porphyria. Br. Med. J. 2:310-312.

25. Strand, L.J., Felsher, B.F., Redeker, A.G., and Marver, H.S. 1970. Heme biosynthesis in intermittent acute porphyria: decreased hepatic conversion of porphobilinogen to porphyrins and increased deltaaminolevulinic acid synthetase activity. Proc. Natl. Acad. Sci. USA. 67:1315-1320.

26. Mustajoki, P., et al. 1992. Sustained high plasma 5-aminolaevulinic acid concentration in a volunteer: no porphyric symptoms. Eur.J. Clin. Invest. 22:407-411.

27. Stein, J.A., and Tschudy, D.P. 1970. Acute intermittent porphyria. A clinical and biochemical study of 46 patients. Medicine. 49:1-16.

28. Percy, V.A., and Shanley, B.C. 1977. Porphyrin precursors in blood, urine and cerebrospinal fluid in acute porphyria. S. Afr. Med. J. 52:219-222.

29. Sweeney, V.P., Pathak, M.A., and Asbury, A.K. 1970. Acute intermittent porphyria: increase ALA-synthetase activity during an acute attack. Brain. 93:369-380 